\title{
Pain Management in Prostate Cancer
}

\author{
Ali Eman ${ }^{1}$, Serbülent Gökhan Beyaz ${ }^{2 *}$, Hasan Sağlam ${ }^{3}$, Mustafa Emre Gürcï ${ }^{4}$ \\ ${ }^{1}$ Department of Anesthesiology, Ipekyolu State Hospital of Van, Van, Republic of Turkey \\ ${ }^{2}$ Department of Anesthesiology, Sakarya University Medical School, Sakarya, Republic of Turkey \\ ${ }^{3}$ Department of Urology, Sakarya University Medical School, Sakarya, Republic of Turkey \\ ${ }^{4}$ Ipekyolu State Hospital of Van, Department of Anesthesiology, Van, Republic of Turkey \\ Email: "sgbeyaz@gmail.com
}

Received July 6, 2012; revised August 14, 2012; accepted August 27, 2012

\begin{abstract}
Prostate cancer is the most common urogenital malignity of western communities and is the second leading cause of cancer-related deaths in this population. Pain is often due to bone metastasis in prostate cancer. For the patient diagnosed with cancer and for his family, pain is the most feared aspect of cancer following the likelihood of failure to treat and death. Quality of life is severely impaired together with complaint of pain which arises high rates as $80 \%$ in advanced stage cancers.
\end{abstract}

Keywords: Prostate; Cancer; Pain; Analgesia

\section{Introduction}

For the patient diagnosed with cancer and for his family, pain is the most feraed aspect of cancer following the likelihood of failure to treat and death [1]. In these patients, factors like primary tumor type, presence of metastasis, proximity of the tumor to neural structures, psychological status of the patient play important roles in development and severity of the pain [2]. Quality of life is severely impaired together with complaint of pain which arises high rates as $80 \%$ in advanced stage cancers. Having sufficient knowledge about treatment and control of pain today and also dying of patients before their pain is controlled despite advanced techniques and drugs is disappointing. Treatment is insufficient due to clinicians' lacking of experience and knowledge about assessment and treatment of cancer pain despite sufficient knowledge about the treatment of cancer pain. These shortcomings include not knowing wide spectrum cancer pain syndromes, lacking of a certain treatment protocol, worries about side effects and addiction of opioids among the nurses and the clinicians (opiophobia), legal restriction of opioid use, not knowing the pharmacologic properties of non-opioid analgesics, not inquiring the complaint of pain sufficiently and properly, not knowing interventional pain management methods [3].

\section{Prostate Cancer and Pain}

Prostate cancer is the most common malignant lesion in western male population and is the second leading cause

${ }^{*}$ Corresponding author. of cancer-related deaths in this population [4]. Pain is often due to bone metastasis in prostate cancer. It may also be seen due to perineal pain or obstruction of lower end of ureter and prostatic urethra as the result of local invasion of the prostatic pathology.

Osteoporosis which develops as the result of hormonal treatment and aging increases the risk of bone complications besides metastasis in patients with prostate cancer. Although primary osteoporosis is not common in males, bone mineral density begins to reduce beginning from middle age. Thus many men have osteoporosis at the time of prostate cancer diagnosis. Androgen deprivation, the standard treatment of metastatic prostate cancer, is known to lead to bone loss and hormonal treatment reduces bone mineral density $3 \%-5 \%$ yearly $[5,6]$.

Prostate cancer metastasis to the bones more frequently than any other solid tumors and bone metastasis is seen in approximately $65 \%-75 \%$ of the patients with advanced disease [7,8]. Metastasis is frequently seen in vertebra, bony pelvis and ribs. Skeletal complications increase in prostate cancer when bony metastasis develops. Skeletal complications develop in $30.3 \%$ of prostate cancers with bone metastasis and resistant to hormone and yearly incidence was reported as $12 \%$ [9]. Events related with sceletal system also impair the quality of life of the patients.

Bone metastasis from prostate cancer usually seen as pain, pathologic fractures and spinal cord compression. However pain is not essential in all bone metastasis. Cause of pain in bone metastasis is structural damage, mechanic stress, periosteal strain, microfractures, pres- 
sure on adjacent nerves and tissues and release of chemical mediators like prostaglandin and cytokines [10-12]. Pain may be generalized, continuous or intermittent. It is usually defined as ache, burn sensation or sting. Pain becomes severe at night or when holding heavy things. While the pain is initially mild, it may gradually become severe as the disease advances. Metastasis-related pain is usually somatic type but neuropathic pain may also be added as the result of pressure of tumoral mass on adjacent neural structures or invasion. In that case, burn sensation, pressure or paroxysmal pain may arise in the area of affected nerve. Sensory or motor loss may accompany this and a pain reflecting to the legs may develop. Chemotherapy-related neuropathic pain emerges as dysesthesia and peripheric neuropathy or burn sensation in the hands and the feet.

\section{Cancer-Related Pelvic and Perineal Pain}

Urologic cancers, rectum cancer and lower genital organ cancers are among the causes of perineal pain. Pain is initially visceral and somatic properties are added thereafter. Pain may be resulted from involvement of nerve root, plexus, nerve corpus or branches, lymphatic or vascular system or pressure on those sites.

Pain is seen in perineal region in lower urogenital system cancers. More than one third of perineal pain arises from lower genital malignities.

Pelvic, perineal pain may originate from prostate cancer in cases with urologic cancers. Pain may be related to involvement of the organs crossing pelvic and perineal region. Involvement of genitofemoral, iliohypogastric and ilioinguinal nerves are the cause of severe pain.

\section{Chronic Prostatitis}

Interest on chronic prostatitis has increased in recent years. Quality of life is impaired in correlation with depressive symptoms and severity of pain. Post-ejaculatory pain is accepted as a finding of poor prognosis.

A men-specific marker was seeked in some studies about chronic prostatitis however nothing except some amount of elevation in IL-6 and IL-8 could be found. Prostatic cultures did not differ between the patients with or without chronic pelvic pain.

Benefits of technetium-binding ciprofloxacin are mentioned. Also, detection of a large prostatic calculi, hypersensitivity of sacral dermatomes to cutaneous stimuli are also beneficial for diagnosis. Pain development with intravesical potassium solution is frequently seen in chronic protatitis patients.

Agents like ciprofloxacin, levofloxacin, alpha-agonists, pentason polysulphate may be used for treatment. Biofeedback, prostate ablation using transurethral needle, electrostimulation are the other techniques used.

\section{Assessment of the Patients with Cancer Pain}

The main principle for pain assessment is to believe the complaint of pain. In other words, if the patients says that "I have pain", he has pain. Taking an anamnesis enables to put forward the emotional and psychiatric status of the patient besides providing data about potential causes and mechanisms of the pain. A simple treatment plan must be made for pain while needed tests are being performed.

The following algorithm may be followed for pain assessment [13-15].

1) Believe the complaint of pain.

2) Take a careful anamnesis of pain: question the pain in detail together with the location, duration, characteristic, severity of the pain, factors increasing or decreasing the pain, accompanying symptoms and history of pain including previous treatment modalities, medical history, drugs and allergy.

3) Range the complaint of pain according to significance if the complaint of pain is more than one.

4) Assess the response to and satisfaction from the current and previous analgesic therapy.

5) Assess the psychologic status and alcohol or smoking addiction of the patient.

6) Make a careful medical and neurologic examination

7) Assess the proper diagnostic procedures.

8) Start treatment for the pain in order to facilitate the required studies.

9) Provide regular care and control of the patient to provide patient compliance, to reduce anxiety and to assess treatment, question the response to pain treatment again at each time.

10) Talk to the patient and his family about the potential problems and solutions.

\section{Pain Measurement}

An objective measurement of pain is not possible as it is a subjective concept. Scales used to measure the pain may be uni-dimensional or multi-dimensional (Table 1) and which scale is to be used differs according to the patient or health staff. Uni-dimensional scales are focused on a special parameter like the severity of pain. These scales are simple and beneficial. Visual analogue scale is the most sensitive and beneficial one. Multi-dimensional scales investigate other properties of pain besides its severity $[13,14]$.

\section{Pain Treatment in Patients with Cancer Pain}

Plan of pain treatment is divided into two groups as invasive, non-invasive or pharmacologic or non-pharmacologic, the limits beteen treatment methods is unclear and co-existence of two conditions may be seen frequently [15]. 
Table 1. Scales used for pain measurement.

\begin{tabular}{cc}
\hline Uni-dimensional scales & Multi-dimensional scales \\
\hline Numerical Scales & McGill Pain Questionnaire Form \\
Categorical Scales & Wisconsin Brief Pain Inventory \\
Visual Analogue Scale (VAS) & Memorial Pain Identification Card \\
Visual Analogue & Descriptive Differential Scale \\
TermometerVAT) & West Haven-yale Multi-dimensional \\
Burford Pain Termometer & Pain Inventory \\
\hline
\end{tabular}

Treatment strategy for cancer pain was determined in detail by World Health Organization (WHO). An algorithm of line therapy was put forward in order to protect from side effects and to provide an effective treatment [16-18].

According to this algorithm:

Step 1: Non-opioid analgesics;

Step 2: Weak opioid analgesics + non-opioid analgesics;

Step 3: Potent opioid analgesics + opioid analgesics.

Adjuvan drugs may be added to each line when needed. Application and recognization of this line principle is quite easy and it may provide pain treatment in more than $80 \%$ of patients.

The aim of pain control is painless resting, night sleep not interrupted by pain, to reduce pain in standing position and with movements. In other words, the main goal is to reduce side effects and to improve quality of daily life.

\section{Cancer Pain Syndromes}

Pain syndromes in cancer patients may be gathered under three major groups according to etiology [2,19-21].

1) Invasion or compression of pain-sensitive structures by tumor (bone invasion, compression of nerve roots or nerve plexus, infiltration of nerve tissue and blood vessels of the tumor.

2) Pain arising during cancer therapy;

Surgical therapy-related pain;

Chemotherapy-related pain;

Radiotherapy-related pain.

3) Non-cancer pain in cancer patients.

\section{Pain Treatment}

Pain treatment is done based on analgesic use principles (Table 2).

\section{Non-Opioid Analgesics}

Acetaminophen and nonsteroidal antiinflammatory drugs (NSAIDs) are non-opioid analgesics [22,23], they are the most commonly used analgesics in mild pain alone, they
Table 2. Principles of analgesic use [18].

Analgesic must be chosen in accordance with line principle according to severity of pain.

Cause and quality of pain must be taken into consideration for analgesic selection.

Per oral route must be primarily preferred for analgesic use.

Analgesic dose must be individualized.

Analgesics must be taken with certain intervals before the pain begins.

The patient and his family must be informed about potential side effects.

Adjuvan drug use must not be overlooked and must always be kept in mind.

are effective to reduce opioid dose with additive effect in moderate and severe pain. Ceiling effect, potential side effects and toxicity in high doses restrict their use. NSAIDs act through inhibiting cyclooxygenase enzyme (COX) taking part in prostaglandin synthesis. COX enzyme has two forms. Of them, COX1 mostly regulate renal plasma flow, gastric mucosa protection, platelet aggregation, pain and inflammation and COX2 is responsible for inflammatory cytokine stimulation and hyperalgesia in tissue damage [24-26].

Although acetylsalicylic acid is prototype and an important member of NSAIDs, it is not used in the long term treatment of cancer pain due to high side effect profile.

Paracetamol inhibits only the prostaglandin in central nervous system and does not have antiinfalmmatory property. Therefore it does not have negative peripheral side effects of NSAIDs. It may reduce opioid dose and potential side effects when combined with opioid analgesics. It is recomended at every 6 hours and hepatic toxicty should always be kept in mind in patients who use more than 4 gr and above paracetamol [27-29].

Metamizol is a drug with poor cyclooxygenase and antiinflammatory property and strong analgesic and antipyretic properties. Its analgesic effect is more than aspirin. It also shows additive effect with opioid analgesics like paracetamol. Recommended maximum daily dose is 5 gram. It is particularly recommended in spasmotic pain and it may supress bone marrow. Paracetamol and metamizol are aside from classical NSAIDs [30]. Naproxen is better tolerated than other NSAIDs and is an effective drug in cancer pain. Half-life is approximately 14 hours, recommended daily dose is $1100 \mathrm{mg}$. Piroxicam is an analgesic that may be used as single dose due to its long half-life (45 hours) [15].

Adverse effects like reduction in renal blood flow and micturation, hypertension, thrombocyte dysfunction, asthma crisis, bone marow depression, hepatotoxicity besides frequently seen side effects like gastric irritation, ulcer, bleeding restrict use of NSAIDs [24]. 


\section{Opioid Analgesics}

They are the most potent analgesic agents. They are used in treatment of moderate and severe cancer pain regardless of the mechanism of pain. They act as binding to specific receptors located in medulla spinalis, brain and peripheral nerves. They are usuallay used in combination with NSAIDs at second and third lines recomended by WHO. They inhibit release of transmitters responsible for pain transmission in medulla spinalis and pain perception in the brain. They do not have ceiling effect and maximum doses in a painless individual and they are classified as potent opioids (morphine, hydromorphon, metadon, levorphanol, meperidine, fentanyl) and weak opioids (propoxiphene, codeine, oxycodone, hydrocodone, tramadol). They are administered via per oral, IM, IV, subcutaneous, transdermal, rectal and spinalepidural routes. Side effect and analgesic efficiency balance vary according to the agent used [31-33].

\section{Codeine}

It is effective on moderate-severe pain. Its combination with adjuvant and non-opioid analgesics is effective on cancer pain. Codeine does not cause a significant tolerance and physical addiction besides providing an effective analgesia. It is used via per oral route and may rarely cause nausea, sedation, allergic reaction and dizziness in some patients.

Recommended daily dose for codeine which is in the second line of analgesic therapy is $15-60 \mathrm{mg}$ at every 4 - 6 hours depending on the severity of pain, adjuvant and non-opioid combination.

\section{Fentanyl}

Its onset time and duration of action is $75-125$ fold greater than morphine due to higher lipid solubility. It is recommended via epidural-spinal and transmucosal routes in combination with local anesthetics in the third line of WHO's line therapy. Transdermal form is particularly beneficial in the patients who have trouble with per oral route and the bands are as 72-h forms, onset time is 4 - 12 hours and stable effect develops at 12 - 24 hours, analgesic effect continues 12 hours more after the transdermal band is removed. Side effects may be reversed with naloxone. Transmucosal form is recommended in treatment of breakthrough pain in cancer patients which is seen as sudden pain peaks during the normal course of pain.

\section{Meperidine}

Its potency is one tenth of morphine. It is not used for treatment of chronic pain due to its metabolite, normeperidine, which has short duration of action and may cause convulsions, it is administered for only a few days in treatment of acute pain.

\section{Morphine}

Morphine is accepted as the gold standard among opioid drugs, on the contrary to a belief, it is accepted as the easiest applicable and controllable opioid drug. It may be used via per oral, rectal, intravenous, intrathecal, epidural routes and it may provide a long term analgesia in intrathecal use due to its hydrophillic property. Its active metabolite morphine 6 glucorinide has a more potent analgesic property and thus it is recommended to use carefully in the patients with hepatic and renal insufficiency.

\section{Dose}

Per oral route: It may be used as 10 - $60 \mathrm{mg}$ quid, slow releasing tablets may be used $10-60 \mathrm{mg}$ bid.

Rectal route: 10 - $20 \mathrm{mg}$ at every 4 hours.

Intravenous route: It may be used 2.5 - $15 \mathrm{mg}$ slowly. Subcutaneous and intramuscular doses are the same as intravenous doses.

\section{Tramadol}

It is used as the first line therapy in line therapy of WHO. Its opioid receptor affinity is low and it also inhibits noradrenaline and serotonin reuptake. It is a proper alternative in treatment of cancer pain due to minimal central nervous system side effects, not causing respiratory depression and low addiction potential, showing additive effect with NSAIDs. Its active metabolite is more potent than itself and this causes dose limitation. It has less side effects than typical opioid agonists. The most common side effects include dizziness, nausea, vomiting, sedation, nonspecific central nervous system irritation and coordination disorder and convulsion may occur in high doses. Its half life is approximately 6 hours and it was detected to be safe and effective in max 600 mg daily dose. It may be used via per oral, intravenous, intramuscular, subcutanous routes.

\section{Adjuvant Drugs}

Drugs which are not pharmacologically analgesic but increase the effects of analgesics or used in treatment of symptoms accompanying the pain are named as adjuvant drugs or co-analgesics.

These drugs include topical local anesthetics, neuroleptics, antihistamines, benzodiazepines, anticonvulsants and antidepressant drugs [34].

\section{Anticonvulsants}

While carbamazepine and phenytoin were the corner- 
stones of neuropathic pain treatment until recently, severe side effects restricted the benefits of these drugs. Those side effects include severe cognitive effects which may lead to negative and harmful conditions especially in the elderly, thus patient compliance significantly increased with development of second generation anticonvulsants which are tolerated better and significant improvements occured in treatment options of neuropathic pain.

\section{Gabapentin}

Gabapentin is initially an antiepileptic drug and a structural analogue of gamma-aminobutyric acid (GABA). It is bound to $\alpha 2-\delta$ protein subunit of voltage-dependent calcium channels wich are located widespread in central and peripheral nervous system. This inhibits calcium influx and reduces excitatory neurotransmitters released from pain pathways [35].

Analgesic effect of gabapentin was widely investigated by the surgical community before and it was reported as the result of these studies to have analgesic effect on postoperative pain [36-39]. It was also found to be quite effective in treatment of non-cancer neuropathic pain and cancer-related neuropathic pain. Initial dose of gabapentin is 100 - $300 \mathrm{mg}$ daily and the dose is increased at every three days. Maximum dose is usually $3600 \mathrm{mg}$ daily and the maximum tolerable dose is reached within 1 - 2 weeks. The most common side effects are somnolence and dizziness. Although it is usually well tolerated with a careful titration, somnolence may lead to termination of therapy especially in deteroirated patients.

\section{Pregabalin}

Pregabalin is a lipophillic GABA analogue which has analgesic, anticonvulsant, anxiolytic, sleep modulation opioid sparing effects. It was reported to be effective in many conditions like many neuropathic pain models [40, 41], incisional injury [42] and inflammatory conditions [43] as the successor of gabapentin. In recent studies, there is a gradually increasing interest as it is a part of multimodal analgesia in pain control. Although its mechanism of action is similar to that of gabapentin, its pharmacologic profile is more superior.

Its reducing opioid need, hinder and reduce opioid tolerance, improve the quality of opioid analgesia, reduce respiratory depression, eliminating anxiety and gastric sparing effects make this agent attractive.

Pregabalin has a similar effect to gabapentin. It should be used carefully in the elderly and susceptible individuals. It may be well tolerated if the dose reaches to 75 $\mathrm{mg}$ bid by gradually increasing from $75 \mathrm{mg}$ daily at the end of the first week. Patients rarely wish to exceed 150 mg bid dose due to blurred vision and edema in addition to frequent side effects of anticonvulsants. Gabapentin and pregabalin must certainly be used after renal functions had been checked, preferably after creatinine clearance had been calculated as they are excreted from the kidneys. Pregabalin may be preferred due to less complex titration schedule and possible lower side effect profile [44].

\section{Tapentadol}

Tapentadol affects centrally with its $\mu$ receptor agonist effect and inhibition of noradrenaline reuptake [45-47]. It is 2 - 3 fold less effective than morphine despite 18 fold greater affinity to $\mu$ opioid receptors compared to morphine. It was developed as the result of studies aiming at reducing tolerance seen with opioid doses causing equal analgesic effect. Tapentadol is a novel analgesic with central effect and side effect incidence is lower than that of opioids. It was initially formulated as immediaterelease preparation and approved as potent Schedule II analgesic by the US Food and Drug Administration (FDA). It is also the first analgesic developed since the recent 25 years for management of moderate and severe acute pain [48].

Tapentadol has two different forms of which one is tapentadol immediate-release 50,75 and $100 \mathrm{mg}$ tablets and they provide an analgesia lasting for 4 - 6 hours. Tapentadol was accepted to have an equal analgesic potency with hydrocodone and oxycodone, between tramadol and morphine. Tapentadol was seen to provide a similar analgesia with immediate-release oxycodone [46]. It was also found as effective as oxycodone in the patients suffering from osteoarthritis and chronic low back pain [49]. Besides, its analgesic efficacy was shown in inflammatory, somatic and neuropathic pain and it was reported to have a better gastrointestinal tolerability than opioids (nausea, vomiting, constipation) $[35,50]$.

The second form is tapentadol extended-relase which may be effective for about 12 hours for the patients 18 years and above with moderate or severe pain. It is used twice daily. Tolerance begins slowly in chronic use and it significantly delays the beginning of tolerance compared to morphine [51]. It is contraindicated in the patients with severe asthma, paralytic ileus and who use monoamainooxydase inhibitors.

\section{Steroids}

Steroids inhibit prostaglandin synthesis, reduce tumorrelated edema and inflammation. They have special use areas like inflammation control, antiemetic effect, improvement of anorexia and cachexia in pain management and paliative care. They are particularly indicated in the pain related with bone metastasis, increased intracranial 
pressure, spinal cord compression, liver metastasis, soft tissue infiltration [52]. Usually low dose corticosteroid regimen is applied (prednisone $10-30 \mathrm{mg}$ or deaxamethasone 2 - $4 \mathrm{mg}$ daily).

Most steroids primarily act as reducing inflammatory mediators when used systemically. Usually a depot steroid is used in intraarticular injections, localized myofascial and trigger point injections. These approaches enable higher local doses without causing systemic side effects. Depot steroids are typically used together with local anesthetics for various nerve blocks.

Patients must be assessed in detail, age, physcial condition, hepatic and renal functions of the patients, accompanying diseases, drug interactions must be considered and the patients must be followed up carefully. Myopathy, hyperglycemia, weight gain and dysphoria may develop as the result of long term steroid treatment. Risk of peptic uler increases when used together with NSAIDs.

\section{Biphosphonates}

Biphosphonates reduce bone resorption through inhibiting osteoclastic activity in the patients with bone metastasis-related pain. They were detected to reduce pain development and pathologic fractures when used regularly. The third generation biphosphonate, zolendronic acid was reported to have the potential to prevent bone complications of prostate cancer but to be insufficient for control of bone pain [53].

\section{Hormonal Therapy}

Androgen deprivation is the first choice of treatment modality in painful bone metastasis of androgen-sensitive prostate cancer however resistance may develop against hormone therapy $2-3$ years later.

\section{Radiotherapy}

Radiotherapy is the mainstay in treatment of bone metastasis, prevention of spinal cord and nerve root compression. External beam radiotherapy is seen to be very effective in paliation of pain in bone metastasis. Radiotherapy is considered to relieve pain by inhibiting release of chemical pain mediators and reducing tumor mass. In treatment of bone metastasis, while response is obtained in more than $80 \%$ of patients with radiotherapy, full response could not be obtained in $15 \%$ - 40\%. Its effect begins mean approximately three weeks and continues for 13 - 24 weeks $[54,55]$.

\section{Radiopharmaceuticals}

Systemic radiopharmaceuticals uptaken in the bone are known to have effects on palliation and delaying emerg- ence of new symptomatic sites in the patients who have widespread symptomatic bone metastasis. The most widely used radiopharmaceutical is strontium- 89 in the patients with hormone-resistant prostate cancer who have uncontrollable painful bone metastasis in both sides of diaphragm [56,57]. Samarium 153 is another radiopharmaceutical agent which was shown to be effective in control of bone metastasis-related pain.

\section{Interventional Methods Used in Treatment of Cancer Pain}

There is the indication for invasive therapy if pain continues despite proper doses of analgesics or side effects of drugs cannot be tolerated. Patient selection must be done carefully and the procedures must be applied by experienced specialists as invasive methods have severe side effects. These methods can mainly be classified as anesthetic and surgical methods [58-60].

\section{Nerve Blocks}

Response to therapy must certainly be evaluated with repeated local anesthetic blocks before permanent neurolytic blocks are done besides general rules valid for interventional methods. Celiac plexus block and superior hypogastric block may be beneficial in urologic malignities.

Celiac plexus block provides an effective pain control in upper abdominal pain and low back pain, reduces analgesic need, facilitates the treatment of constipation, a frequent complication of opioid use by increasing bowel movements. Superior hypogastric block is a quite effective and beneficial method for elimination of pain and tenesmus due to rectum and lower urogenital tract malignities.

\section{Percutaneous Cordotomy}

Analgesia may be provided on the contralateral body half by making a destruction in spinothalamic tract using RFA method.

\section{Neuroaxial Catheter Applications}

This may be considered as the 4 th line following potent opioid use in analgesic line therapy of WHO. Opioids provide a longer analgesia when administered via epidural or intrathecal route $[61,62]$. They are mainly administered in three ways: In the first method, a subcutaneous tunnel is opened after the epidural catheter had been placed to a proper site for the pain, the catheter is used by inserting a bacteria filter. In the second method, the aforementioned tunnel is extended to axillary line, it is inserted to a port placed subcutaneously instead of the bacteria filter, injections are done via this port when 
needed. Small devices which provide automatic doses are used instead of port in the third method. Which method will be used is decided according to the patient. Analgesia via catheter is usually provided with morphine, both morphine dose and the pain developing with movements reduce by adding a local anesthetic to morphine. Fibrosis developing on the tip of the epidural catheter makes injections from the catheter very difficult in some cases, and accompanying burn sensation may cause severe disturbance in the patients. On the other hand, it has advantages like less infection risk, providing dermatomal analgesia.

Opioid-related urinary retention, nausea, vomiting, itching, respiratory depression, local anesthetic-related motor-sensory block, orthostatic hypotension may develop. The most severe side effect is infection. Obstruction, break and CSF leakage may develop.

Extended release epidural morphine (EREM) that can be administered in a single dose and we consider to be beneficial in cancer patients was put on the market. EREM was formulated so as to be administered to epidural region at lumbar level. It was reported to provide a long standing analgesia in a few studies [35].

In conclusion, the aim in prostate cancer patients will be to achieve the best possible analgesia with minimum drug dose, minimum side effect and minimally invasive method regardless of the method chosen for pain management.

\section{REFERENCES}

[1] F. J. Keefe, A. P. Abernethy and C. L. Campbell, "Psychological Approaches to Understanding and Treating Disease-Releated Pain," Annual Review of Psychology, Vol. 56, 2005, pp. 1-22.

doi:10.1146/annurev.psych.56.091103.070302

[2] D. M. Fitzgibbon and C. R. Chapman, "Cancer Pain: Asessment and Diagnosis," In: J. D. Loeser, H. Butler, R. Chapman and D. C. Turk, Eds., Bonica's Managment of Pain, 3rd Edition, Lippincott Williams and Wilkins, Philedelphia, 2001, pp. 623-658.

[3] R. Payne, "Choronic Pain: Challenges in the Assesment and Managment of Cancer Pain," Journal of Pain and Symptom Management, Vol. 19, No. 1, 2000, pp. 12-15. doi:10.1016/S0885-3924(99)00123-2

[4] S. L. Parker, T. Tong, S. Bolden and P. A. Wingo, "Cancer Statistics, 1997," CA Cancer Journal Clinics, Vol. 47, No. 1, 1997, pp. 5-27. doi:10.3322/canjclin.47.1.5

[5] S. Ziaran, F. M. Goncalves and J. S. Breza, "Bone Mineral Density, Pathological Fractures and Bisphosphonate Therapy in Prostate Cancer Patients on Androgen Deprivation Therapy," Endocrine Regulations, Vol. 45, No. 4, 2011, pp. 199-204. doi:10.4149/endo $2011 \quad 04 \quad 199$

[6] R. W. Ross and E. J. Smal, "Osteoporosis in Men Treated with Androgen Deprivation Therapy for Prostate Cancer,"
Journal of Urology, Vol. 167, No. 5, 2002, pp. 19521956. doi:10.1016/S0022-5347(05)65060-4

[7] R. E. Coleman, "Clinical Features of Metastatic Bone Disease and Risk of Skeletal Morbidity," Clinical Cancer Research, Vol. 12, No. 20, 2006, pp. 6243-6249. doi:10.1158/1078-0432.CCR-06-0931

[8] R. E. Coleman, "Metastatic Bone Disease: Clinical Features, Pathophysiology and Treatment Strategies," Cancer Treatment Reviews, Vol. 27, No. 3, 2001, pp. 165-176. doi: $10.1053 /$ ctrv.2000.0210

[9] A. Berruti, L. Dogliotti, R. Bitossi, G. Fasolis, G. Gorzegno, M. Bellina, et al., "Incidence of Skeletal Complications in Patients with Bone Metastatic Prostate Cancer and Hormone Refractory Disease: Predictive Role of Bone Resorption and Formation Markers Evaluated at Baseline," Journal of Urology, Vol. 164, No. 4, 2000, pp. 1248-1253. doi:10.1016/S0022-5347(05)67149-2

[10] C. Ripamonti and F. Fulfaro, "Malignant Bone Pain: Pathophysiology and Treatments," Current Review of Pain, Vol. 4, No. 3, 2000, pp. 187-196. doi:10.1007/s11916-000-0078-3

[11] S. Buga and J. E. Sarria, "The Management of Pain in Metastatic Bone Disease," Cancer Contrology, Vol. 19, No. 2, 2012, pp. 154-166.

[12] R. Payne, "Mechanisms and Management of Bone Pain," Cancer, Vol. 80, No. 1, 1997, pp. 1608-1613. doi:10.1002/(SICI)1097-0142(19971015)80:8+<1608::AI D-CNCR11>3.0.CO;2-3

[13] M. Uyar and Y. Yildırım, "Assesment of the Patient with Painful,” In: F. Tüzüner, Ed., Anesthesia, Intensive Care, Pain Management, Nobel Publishing, Ankara, 2010, pp. 1523-1533.

[14] T. Aldemir, "Pain Measurement in Patients with Painful," In: S. Erdine, Ed., Pain, 2nd Edition, Nobel Publishing, Istanbul, 2007, pp. 93-97.

[15] I. Aşık, "Cancer Pain Treatment," In: F. Tüzüner, Ed., Anesthesia, Intensive Care, Pain management, Nobel Publishing, Ankara, 2010, pp. 1613-1633.

[16] D. F. Zech, S. Grond, J. Lynch, D. Hertel and K. A. Lehmann, "Validation World Healt Organization Guidelines for Cancer Pain Relief: A 10 Year Prospective Study," Pain, Vol. 63, 1995, pp. 65-76. doi:10.1016/0304-3959(95)00017-M

[17] World Health Organization, "Cancer Pain Relief," WHO, Geneva, 1986.

[18] G. W. Hanks, F. deConno and N. Cherny, "Morphine and Alternative Opioids in Cancer Pain: The EAPC Recommendations," British Journal of Cancer, Vol. 84, 2001, pp. 587-593. doi:10.1054/bjoc.2001.1680

[19] N. I. Chernyand R. K. Portenoy, "Cancer Pain: Principles of Assessment and Syndromes," In: R. Melzack and P. D. Wall, Eds., Textbook of Pain, 4th Edition, Churchill Livingstone, Edinburg, 1999, pp. 1017-1064.

[20] M. J. Lema, M. R. Day and D. P. Myers, "Cancer Pain," In: P. R. Raj, Ed., Practical Management of Pain, 3rd Edition, Mosby, St. Louis, 2000, pp. 241-253.

[21] N. Cherny, "Cancer Pain Syndromes," In: R. Melzack and P. D. Wall, Eds., Handbook of Pain Management, Chur- 
chill Livingstone, Edinburg, 2003, pp. 603-639. doi:10.1016/B978-0-443-07201-7.50046-1

[22] C. Hebbes and D. Lambert, "Non-Opioid Analgesics," Anaesthesia \& Intensive Care Medicine, Vol. 12, No. 2, 2011, pp. 69-72. doi:10.1016/j.mpaic.2010.10.022

[23] J. P. Barbara, "Opioid Mechanisms and Opioid Drugs," Anaesthesia \& Intensive Care Medicine, Vol. 6, No. 1, 2005, pp. 25-29.

[24] N. Rawal, "Postoperative Pain Management," In: S. Erdine, Ed., Pain, 2nd Edition, Nobel Publishing, Istanbul, 2007, pp. 118-135.

[25] D. M. Fitzgibbon, "Cancer Pain: Management," In: J. D. Loeser, H. Butler, R. Chapman and D. C. Turk, Eds., Bonica's Management of Pain, 3rd Edition, Lippincott Williams and Wilkins, Philadelphia, 2001, pp. 659-673.

[26] N. I. Cherny and R. K. Portenoy, "Practical Issues in the Management of Cancer Pain," In: P. D. Wall and R. Melzack, Eds., Textbook of Pain, 4th Edition, Churchill Livingstone, Edinburg, 1999, pp. 1479-1523.

[27] R. Botting and S. S. Ayoub, "COX3 and the Mechanism of Action of Paracetamol/Acetaminophen," Prostaglandins, Leukotriens and Essential Fatty Acids, Vol. 72, 2005, pp. 85-87. doi:10.1016/j.plefa.2004.10.005

[28] R. M. Botting, "Mechanism of Action of Acetaminophen: Is There a Cyclooxygenase 3?" Clinical Infectious Diseases, Vol. 31, No. 5, 2000, pp. S202-S210. doi: $10.1086 / 317520$

[29] G. G. Graham, K. F. Scott and R. O. Day, "Tolerability of Paracetamol,” Drug Safety, Vol. 28, 2005, pp. 227-240. doi:10.2165/00002018-200528030-00004

[30] R. N. Brogden, "Pyrazolone Derivatives," Drugs, Vol. 32, No. 14,1986 , pp. $60-70$. doi:10.2165/00003495-198600324-00006

[31] K. Keskinbora, "Opioid Analgesics," In: S. Erdine, Ed., Pain, 2nd Edition, Nobel Publishing, Istanbul, 2007, pp. 581-604.

[32] C. Sweeney and E. Bruera, "Opioids," In: R. Melzack and P. D. Wall, Eds., Handbook of Pain Management, Churchill Livingstone, Edinburg, 2003, pp. 377-396. doi:10.1016/B978-0-443-07201-7.50028-X

[33] S. A. Schug and N. Gandham, "Opioids: Clinical Use," In: S. B. McMahon and M. Koltzenberg, Eds., Wall and Melzack's Textbook of Pain, 5th Edition, Elsevier Churchill Livingstone, Beijing, 2006, pp. 443-457. doi:10.1016/B0-443-07287-6/50033-3

[34] D. Lussier, A. G. Huskey and P. K. Portenoy, "Adjuvant Analgesic in Cancer Pain Management," The Oncologist, Vol. 9, 2004, pp. 571-591. doi:10.1634/theoncologist.9-5-571

[35] S. G. Beyaz, F. Bayar and A. F. Erdem, "Acute Postoperative Pain," Journal of Anesthesia \& Clinical Research, 2011, in press.

[36] A. Turan, B. Karamanlioglu, D. Memis, P. Usar, Z. Pamukcu and M. Ture, "The Analgesic Effects of Gabapentin after Total Abdominal Hysterectomy," Anesthesia \& Analgesia, Vol. 98, 2004, pp. 1370-1373. doi:10.1213/01.ANE.0000108964.70485.B2
[37] K. Y. Ho, T. J. Gan and A. S. Habib, "Gabapentin and Postoperative Pain: A Systematic Review of Randomized Controlled Trials," Pain, Vol. 126, 2006, pp. 91-101. doi:10.1016/i.pain.2006.06.018

[38] A. Turan, G. Kaya, B. Karamanlioglu, Z. Pamukcu and C. C. Apfel, "Effect of Oral Gabapentin on Postoperative Epidural Analgesia," British Journal of Anaesthesia, Vol. 96, 2006, pp. 242-246. doi:10.1093/bja/aei294

[39] M. G. Rorarius, S. Mennander, S. Rintala, A. Puura, P. Suominen, R. Pirhonen, et al., "Gabapentin for the Prevention of Postoperative Pain after Vaginal Hysterectomy," Pain, Vol. 110, 2004, pp. 175-181. doi:10.1016/j.pain.2004.03.023

[40] S. Y. Kim, J. W. Song, B. Park, S. Park, Y. J. An and Y. H. Shim, "Pregabalin Reduces Post-Operative Pain after Mastectomy: A Double-Blind, Randomized, PlaceboControlled Study," Acta Anaesthesiologica Scandinavica, Vol. 55, No. 3, 2011, pp. 290-296. doi:10.1111/j.1399-6576.2010.02374.x

[41] I. Gilron, D. Wajsbrot, F. Therrien and J. Lemay, "Pregabalin for Peripheral Neuropathic Pain: A Multicenter, Enriched Enrollment Randomized Withdrawal PlaceboControlled Trial," Clinical Journal of Pain, Vol. 27, No. 3, 2011, pp. 185-193. doi:10.1097/AJP.0b013e3181fe13f6

[42] D. K. Baidya, A. Agarwal, P. Khanna and M. K. Arora, "Pregabalin in Acute and Chronic Pain," Journal of Anaesthesiology Clinical Pharmacology, Vol. 27, No. 3, 2011, pp. 307-314. doi:10.4103/0970-9185.83672

[43] D. Ceyhan and M. S. Güleç, "Is Postoperative Pain Only a Nociceptive Pain?" Agriculture, Vol. 22, No. 2, 2010, pp. 47-52.

[44] R. H. Dworkin, A. B. O'Connor and J. Audette, "Recommendations for the Pharmacological Management of Neuropathic Pain: An Overview and Literature Update," Mayo Clinical Proceedings, Vol. 85, 2010, pp. 3-14. doi:10.4065/mcp.2009.0649

[45] C. T. Hartrick and R. J. Rozek, "Tapentadol in Pain Management: A $\mu$-Opioid Receptor Agonist and Noradrenaline Reuptake Inhibitor," CNS Drugs, Vol. 25, No. 5, 2011, pp. 359-370. doi:10.2165/11589080-000000000-00000

[46] W. E. Wade and W. J. Spruill, "Tapentadol Hydrochloride: A Centrally Acting Oral Analgesic," Clinical Therapy, Vol. 31, No. 12, 2009, pp. 2804-2818. doi:10.1016/j.clinthera.2009.12.003

[47] M. Afilalo, J. U. Stegmann and D. Upmalis, “Tapentadol Immediate Release: A New Treatment Option for Acute Pain Management," Journal of Pain Research, Vol. 3, 2010, pp. 1-9.

[48] N. Vadivelu, A. Timchenko, Y. Huang and R. Sinatra, "Tapentadol Extended-Release for Treatment of Chronic Pain: A Review," Journal of Pain Research, Vol. 4, 2011, pp. 211-218.

[49] G. Vorsanger, J. Xiang, A. Okamoto, D. Upmalis and B. Moskovitz, "Evaluation of Study Discontinuations with Tapentadol Inmmediate Release and Oxycodone Immediate Release in Patients with Low Back or Osteoarthritis Pain," Journal of Opioid Management, Vol. 6, No. 3, 
2010, pp. 169-179. doi:10.5055/jom.2010.0015

[50] M. Etropolski, K. Kelly, A. Okamoto and C. Rauschkolb, "Comparable Efficacy and Superior Gastrointestinal Tolerability (Nausea, Vomiting, Constipation) of Tapentadol Compared with Oxycodone Hydrochloride," Advances in Therapy, Vol. 28, No. 5, 2011, pp. 401-417. doi:10.1007/s12325-011-0018-0

[51] M. S. Cepeda, A. Sutton, R. Weinstein and M. Kim, "Effect of Tapentadol Extended Release on Productivity: Results from an Analysis Combining Evidence from Multiple Sources," Journal of Pain, 2011, in press.

[52] S. Mercadante, F. Fulfaro and A. Casuccio, "The Use of Corticosteroids in Home Palliative Care," Support Care Cancer, Vol. 9, No. 5, 2001, pp. 386-389. doi: $10.1007 / \mathrm{s} 005200000218$

[53] F. Saad, D. M. Gleason, R. Murray, S. Tchekmedyian, P. Venner, L. Lacombe, et al., "A Randomized, PlaceboControlled Trial of Zoledronic Acid in Patients with Hormone-Refractory Metastatic Prostate Carcinoma," Journal of the National Cancer Institute, Vol. 94, No. 19, 2002, pp. 1458-1468. doi:10.1093/jnci/94.19.1458

[54] M. N. Gaze, C. G. Kelly, G. R. Kerr, A. Cull, V. J. Cowie, A. Gregor, et al., "Pain Relief and Quality of Life Following Radiotherapy for Bone Metastases: A Randomised Trial of Two Fractionation Schedules," Radiotherapy \& Oncology, Vol. 45, No. 2, 1997, pp. 109-116. doi:10.1016/S0167-8140(97)00101-1

[55] J. S. Wu, A. Bezjak, E. Chow and P. Kirkbride, "Primary treatment Endpoint Following Palliative Radiotherapy for Painful Bone Metastases: Need for a Consensus Definition?" Clinical Oncology (Royal College of Radiologists), Vol. 14, No. 1, 2002, pp. 70-77. doi:10.1053/clon.2001.0012

[56] M. D. Brundage, J. M. Crook and H. Lukka, "Use of Strontium-89 in endocrine-Refractory Prostate Cancer Metastatic to Bone, Provincial Genitourinary Cancer Disease Site Group," Cancer Prevention and Control, Vol. 2, No. 2, 1998, pp. 79-87.
[57] A. T. Porter, A. J. McEwan, J. E. Powe, R. Reid, D. G. McGowan, H. Lukka, et al., "Results of a Randomized Phase-III Trial to Evaluate the Efficacy of Strontium-89 Adjuvant to Local Field External Beam Irradiation in the Management of Endocrine Resistant Metastatic Prostate Cancer," International Journal of Radiation Oncology \& Biology \& Physics, Vol. 25, No. 5, 1993, pp. 805-813. doi:10.1016/0360-3016(93)90309-J

[58] D. Niv and M. Gofeld, "Percutaneus Neural Destructive Techniques," In: J. Michael, M. J. Cousins, T. T. Horlockert, D. B. Carr and P. O. Bridenburg, Eds., Cousins and Bridenbaugh's Neural Blockade in Clinical Anesthesia and Pain Medicine, 4th Edition, Lippinocott Williams and Wilkins, Philadelphia, 2009, pp. 991-1036.

[59] S. E. Brogan, "Interventional Pain Therapies," In: S. M. Fishman, J. C. Balantyne and J. P. Rathmell, Eds., Bonica's Management of Pain, 4th Edition, Lippincott Williams and Wilkins, Philadelphia, 2010, pp. 605-618.

[60] M. Curatolo and N. Bogduk, "Diagnostic and Therapeutic Nerve Blocks," In: S. M. Fishman, J. C. Balantyne and J. P. Rathmellb, Eds., Bonica's Management of Pain, 4th Edition, Lippincott Williams and Wilkins, Philadelphia, 2010, pp. 1401-1423.

[61] P. C. Phan, "Treatment of Cancer Pain: Role of Neural Blockade and Neuromodulation," In: J. Michael, M. J. Cousins, T. T. Horlockertt, D. B. Carr and P. O. Bridenburg, Eds., Cousins \& Bridenbaugh's Neural Blockade in Clinical Anesthesia and Pain Medicine, 4th Editon, Lippincott Williams and Wilkins, Philadelphia, 2009, pp. 1111-1153.

[62] J. P. Rathmell, C. A. Pino and S. Ahmed, "Spinal Pain and the Role of Neural Blockade," In: J. Michael, M. J. Cousins, T. T. Horlockertt, D. B. Carr and P. O. Bridenburg, Eds., Cousins and Bridenbaugh's Neural Blockade in Clinical Anesthesia and Pain Medicine, 4th Edition, Lippinocott Williams and Wilkins, Philadelphia, 2009, pp. 1063-1111. 